\title{
Advanced Characterisation of Nanocomposite Coatings
}

\author{
M.A. Baker \\ The Surface Analysis Laboratory, School of Engineering, University of Surrey, Guildford, Surrey, \\ GU2 7XH, UK \\ Email:m.baker@surrey.ac.uk
}

\begin{abstract}
Nanocomposite coatings are systems comprised of two or more phases. Such multiphase coatings are becoming increasingly important as they offer the possibility of tailoring the coating architecture and achieving exciting new properties. An understanding of the coating nanostructure is important to complete the classic processing-structure-properties relationship and expedite the development of novel systems. However, comprehensive structural and chemical characterisation of such nanostructured coatings remains a considerable challenge. In this paper, results on three nanocomposite coating systems are presented (Ti-Al-B-N, Ti-B-C and Cr-Cu-N). The use of XRD, TEM and XPS for phase identification, determination of the relative phase fraction, grain size and structural defects are described. The accordance (or not) of the phase composition and relative phase fraction with the equilibrium phase diagram for these systems is examined. Specific interesting features of the spectra and micrographs are interpreted and their nanostructural significance discussed. Correlations are made between the nanostructure and mechanical properties.
\end{abstract}




\section{Introduction}

Nanocomposite coatings are multiphase nanocrystalline based systems. The coatings can be deposited by physical and chemical vapour deposition (PVD and CVD) methods. Nanostructuring and multiphase compositions leads to a greater flexibility in tailoring properties, enhanced mechanical performance [e.g.1-4], and the possibility to develop self-adaptive coatings for tribological applications [5].

To form a multiphase nanostructure, there needs to be a thermodynamic driving force for phase separation. Consequently, consideration of the phase diagram is an integral part of the coating design process. However, as vapour deposition techniques have rapid quenching rates, they are non-equilibrium processes. The formation of metastable phases and the presence of defective structure need to be identified for the process-structureproperty relationship to be fully characterised.

To understand and improve the properties of nanocomposite coatings, characterisation of the coating chemical composition, phase composition and nanostructure are paramount. The chemical composition can be determined using many techniques, such as X-ray photoelectron spectroscopy (XPS), Auger electron spectroscopy (AES), Rutherford backscattering spectrometry (RBS), energy dispersive X-ray analysis (EDX) etc. The nanocrystalline phase can be identified using diffraction methods, such as X-ray diffraction (XRD) or electron diffraction. Average grain sizes can be determined from analysing XRD peaks and applying the Scherrer formula or Warren-Averbach approach 
and the nanocrystallite size and spatial distribution within the coating bulk can be studied using transmission electron microscopy (TEM). However, when the grain size drops below $\approx 1 \mathrm{~nm}$, the XRD peaks become strongly broadened, resulting in the spectrum often being difficult to interpret. In such cases, the coating nanostructure is often termed 'X-ray amorphous'. Diffraction techniques offer little or no information on the presence or composition of phases in the coatings which are either X-ray amorphous or truly amorphous. The presence and composition of such phases generally needs to be determined by other techniques, the most useful being XPS, but some information is also obtainable using optical methods such as Fourier transform infra-red spectroscopy (FTIR) or Raman spectroscopy.

Diffraction techniques are also unable to provide information on the relative phase fraction, due to diffraction spectra being inherently non-quantifiable. As both nanocrystalline and amorphous phases can often be separately identified and the spectra easily quantified, XPS provides a good method for determining relative (atomic) phase fractions.

By reviewing the results of investigations into various coating systems undertaken by the author and his co-workers, this paper will describe how diffraction and electron spectroscopic techniques can be employed to give a reasonably comprehensive characterisation of the structure and relative phase fraction of nanocomposite coatings. Only a brief summary of the deposition conditions and mechanical properties of these coatings are given - full details are available in the references cited. 


\section{Experimental}

Analytical results from three techniques will be presented, XRD, XPS and TEM. XRD spectra were recorded using a glancing angle XRD (GAXRD) instrument constructed inhouse at an incident angle of $0.5^{\circ}$ employing unmonochromated $\mathrm{Cu}$ radiation. A highprecision variable slit before the sample and Soller slit collimator between the sample and detector were used for angular resolution. A solid-state detector was employed to isolate the $\mathrm{K} \alpha$ doublet and reduce background noise to a minimum. Grain sizes were determined by adopting the single line method described by Kiejser [6] based on the least-squares fitting of broadened peaks to a pseudo-Voigt function.

All XPS measurements were acquired at constant analyser energy. The Ti-Al-B-N coatings were analysed using a VG Sigmaprobe, employing an Al K $\alpha$ source and hemispherical analyser. A pass energy of $30 \mathrm{eV}$ and step of $0.1 \mathrm{eV}$ were used. For the TiB-C coatings, a Riber Nanoscan 50 was employed, with the MAC2 semi-imaging analyser set at an energy resolution of $0.5 \mathrm{eV}$ and step of $0.1 \mathrm{eV}$. Both instruments were calibrated on the $\mathrm{Cu} 2 \mathrm{p}_{3 / 2}$ peak at $932.7 \mathrm{eV}$ and the $\mathrm{Au} 4 \mathrm{f}_{7 / 2}$ peak at $84.0 \mathrm{eV}$. Surface hydrocarbon was used for charge referencing purposes, at a binding energy of $284.8 \mathrm{eV}$. Prior to analysis, the surface oxide was removed using a $3 \mathrm{keV}$ argon ion beam. Curve fitting was performed after a Shirley background subtraction by non-linear least squares fitting of a mixed Gaussian/Lorentzian function. Quantification involved sensitivity 
factors based on standard materials for the Riber Nanoscan 50 and transmission function modified Wagner sensitivity factors on the VG Sigmaprobe.

The TEM work was performed on a $\mathrm{LaB}_{6}$ Philips CM200 operated at $200 \mathrm{keV}$. Plan-view specimens were prepared by thinning through the substrate, leaving the surface of the coating sufficiently thin for investigation. Final thinning was undertaken on a Gatan precision ion polishing system at an accelerating voltage of $5 \mathrm{keV}$.

\section{Results}

\subsection{The Ti-B-N and Ti-Al-B-N Systems}

Much work has been undertaken on the Ti-B-N and Ti-Al-B-N coatings systems. The equilibrium phase diagram for Ti-B-N has been given by Novotny et al [7]. For Ti-Al-B$\mathrm{N}$, this diagram can be modified to account for the known substitution of $\mathrm{Al}$ for $\mathrm{Ti}$ in the f.c.c. lattice of TiN, as shown in Fig. 1. Inspection of the phase diagram shows that the Ti-B-N and Ti-Al-B-N systems contain many interesting phases. Coatings deposited with compositions along the $\mathrm{Ti}(\mathrm{Al}) \mathrm{N}-\mathrm{TiB}_{2}$ and $\mathrm{Ti}(\mathrm{Al}) \mathrm{N}-\mathrm{BN}$ quasi-binary sections and in the ternary $\operatorname{Ti}(\mathrm{Al}) \mathrm{N}, \mathrm{TiB}_{2}, \mathrm{BN}$ region have all been of particular interest to researchers.

A range of Ti-Al-B-N coatings were deposited by electron beam evaporation at a substrate temperature of $450{ }^{\circ} \mathrm{C}$ with nominal compositions lying on the (Ti,Al)N-BN 
quasi-binary section [8]. The elemental compositions of these coatings measured by XPS are given in Table 1 and are marked as circles on the phase diagram in Figure 1. Knowing the coating stoichiometry, $(\mathrm{Ti}, \mathrm{Al}) \mathrm{B}_{\mathrm{x}} \mathrm{N}_{\mathrm{y}}$, the phase compositions can be calculated from the following equations:

$$
C_{T_{i B_{2}}}=\frac{(1+x-y)}{(1+x+2 y)} \quad C_{\text {TiAlN }}=\frac{(2-x+y)}{(1+x+2 y)} \quad C_{B N}=\frac{(-2+x+2 y)}{(1+x+2 y)}
$$

where $x$ and $y$ correspond to the $\mathrm{B}$ and $\mathrm{N}$ stoichiometry values respectively [9]. The calculated phase compositions are given in Table 1. According to the phase diagram, coating 1 should have a nominal phase composition of $42 \%(\mathrm{Ti}, \mathrm{Al}) \mathrm{N}$ and $57 \% \mathrm{BN}$, with the $(\mathrm{Ti}, \mathrm{Al}) \mathrm{N}$ fraction increasing for the other coatings, up to $92 \%$ for coating 5 . In addition, a small fraction of $\mathrm{TiB}_{2}$ may be expected in all coatings. The XRD spectra are presented in Figure 2. The only identifiable nanocrystalline phase present is f.c.c. $(\mathrm{Ti}, \mathrm{Al}) \mathrm{N}$. Thus, the BN phase must be assumed to be amorphous. For coatings $1-3$, the $(\mathrm{Ti}, \mathrm{Al}) \mathrm{N}$ average grain size increases as the $\mathrm{BN}$ phase fraction decreases, as expected from competitive phase growth considerations. This trend does not continue for coatings 4 and 5, most probably due to the change in texture. Peak fitted XPS B $1 \mathrm{~s}$ and N 1s core level spectra are shown in Fig. 3. The B 1s peak positions of $190.5 \mathrm{eV}$ and $187.6 \mathrm{eV}$ and $\mathrm{N}$ 1s peak positions of $396.9 \mathrm{eV}$ and $397.9 \mathrm{eV}$ are in good agreement with those expected for $\left(\mathrm{BN}\right.$ and $\left.\mathrm{TiB}_{2}\right)$ and $((\mathrm{Ti}, \mathrm{Al}) \mathrm{N}$ and $\mathrm{BN})$ respectively [9]. To obtain a good peak fit of both the $\mathrm{B}$ and $\mathrm{N}$ 1s peaks, a third component is required, corresponding to sub-oxide species. A comparison of the relative phase fraction calculated from the phase diagram to that actually present in the coatings is given in Table 1 . The agreement is good. This is 
the case both for these Ti-Al-B-N and other Ti-B-N coatings which have a three phase $\mathrm{TiB}_{2}$, TiN and BN composition [8-10].

The B 1s region for these Ti-Al-B-N coatings shows the emergence of a third peak at low binding energies for coatings with low B concentrations (Fig. 4). This peak has a binding energy of $185.9 \mathrm{eV}$ and an unusually small FWHM. There is no B 1 s peak listed with such a low binding energy in the NIST XPS database [11]. For inorganic compounds there is generally a good correlation between core level binding energy and electronegativity of the ligand. Consideration of the electronegativities and binding energies for various B ligands has enabled an extrapolation of the B 1s binding energy down to $185.9 \mathrm{eV}$ [8]. For such a binding energy, a ligand with a Pauling electronegativity of approximately 1.6 would be expected. Ti has a Pauling electronegativity of 1.54. Interestingly, however, the binding energies of the Ti borides, $\mathrm{TiB}_{2}$ and $\mathrm{TiB}$, (and elemental B) occur at $187.9 \pm 0.1 \mathrm{eV}$, i.e. at much higher binding energies than $185.9 \mathrm{eV}$ [12]. These high binding energies result from the strong B-B bonding which exists in both $\mathrm{TiB}_{2}$ and $\mathrm{TiB}$. $\mathrm{B}-\mathrm{B}$ bonding is reported to be significantly stronger than Ti-B and Ti-Ti bonding in both compounds $[13,14]$. The nature of the 185.9 $\mathrm{eV}$ peak thus corresponds to a local environment in which $\mathrm{B}$ atoms are locally bonded to Ti atoms, but are unable to form a B-B network. Within the nanocomposite structure, two possiblities arise (i) B atoms becoming entrapped within the $(\mathrm{Ti}, \mathrm{Al}) \mathrm{N}$ grains and substituting for $\mathrm{N}$ atoms within the (Ti,Al)N structure or (ii) $\mathrm{B}$ atoms located at the grain boundary between two $(\mathrm{Ti}, \mathrm{Al}) \mathrm{N}$ grains . 
Mayrhofer et al have reported the formation of $\operatorname{Ti}(\mathrm{N}, \mathrm{B})$ for $\mathrm{B}$ concentrations up to 17 at.\% [15] and as argued above, the binding energy of $185.9 \mathrm{eV}$ is consistent with the $\mathrm{B}$ atom existing in a local environment of many Ti atoms. Consequently, the most probable origin of this peak is B substituting for $\mathrm{N}$ in the (Ti,Al)N nanocrystallites. The small FWHM may be explained by a reduction in the solid-state phonon broadening caused by the absence of a 3-D periodic structure for the B atoms giving rise to this peak.

The mechanical properties of these TiAlBN coatings are good, with all coatings showing an improvement over commercial TiN and TiAlN in lubricated cutting tests [16]. The performance improved with increasing (Ti,Al)N content and coating 5, with a (Ti,Al)N content of 90 at. $\%$ showed a 2.5 fold increase in lifetime. The incorporation of a small percentage of $\mathrm{B}$ into $(\mathrm{Ti}, \mathrm{Al}) \mathrm{N}$ (less than $1 \%$ of $\mathrm{N}$ atoms replaced by $\mathrm{B}$ for coating 5 ) has no adverse affect on the mechanical properties, on the contrary, age hardening is likely to occur at elevated temperatures [15].

\subsection{The Ti-B-C System}

For coatings which require a good resistance to sliding wear, there is an obvious benefit in reducing the friction coefficient. This can be achieved by combining hard and lubricant phases in a nanocomposite coating. The phase diagram for the Ti-B-C system shows the potential of depositing nanocomposite coatings comprised of a hard $\mathrm{TiB}_{2}$ phase and a low-friction diamond-like carbon (DLC) phase (Fig. 5). Ti-B-C coatings were co- 
sputtered from $\mathrm{TiB}_{2}$ and $\mathrm{C}$ targets by magnetron sputtering at a substrate temperature of $150{ }^{\circ} \mathrm{C}[17]$. The coating compositions determined by XPS are shown in Fig. 5. All of the coatings lie close to the $\mathrm{TiB}_{2}-\mathrm{C}$ tie line, but a deficiency in $\mathrm{B}$ has resulted in their location within the $\mathrm{TiB}_{2}$-TiC-C three phase region. The $\mathrm{C}$ concentration increases from 18 at. $\%$ in coating 1 to 90 at.\% in coating 7.

GAXRD spectra for these coatings are presented in Fig. 6. The only nanocrystalline phase present is hexagonal $\mathrm{TiB}_{2}$, there are no peaks indicating the presence of TiC. Grain sizes (determined from the (001) and (101) peaks) decrease from $9.5 \mathrm{~nm}$ at 18 at.\% $\mathrm{C}$ to $1.9 \mathrm{~nm}$ at 61 at.\% C. At higher $\mathrm{C}$ concentrations the coating is amorphous. The $\mathrm{TiB}_{2}$ (001) and (002) peak positions shift to lower angles and the (100) to higher angles as the C concentration increases. XPS C 1s and B 1s spectra from coating 2 (39 at.\% C) are shown in Fig. 7. The $\mathrm{C}$ peak is composed of two components (at 282.9 and $284.5 \mathrm{eV}$ ) and the $\mathrm{B}$ peak one component at $188.0 \mathrm{eV}$. No peak corresponding to $\mathrm{TiC}$ (binding energy $281.9 \mathrm{eV}$ ) was observed. The peak structure was similar for all coatings. The small peaks at higher binding energies correspond to $\mathrm{C}-\mathrm{O}$ and $\mathrm{B}-\mathrm{O}$ bonding.

The $\mathrm{C}$ component at $284.5 \mathrm{eV}$ represents the DLC phase. The $\mathrm{C}$ component at $282.9 \mathrm{eV}$ shows no shift in peak position with $\mathrm{C}$ concentration. However, the binding energy of the B 1s peak progressively shifts to higher values with increasing $\mathrm{C}$ content and for $\mathrm{C}$ contents of approximately $20-40 \%$, the XPS determined stoichiometry is $\operatorname{Ti}(\mathrm{B}, \mathrm{C})_{2.0}[18]$. Considering that the Pauling electronegativities of Ti, B and C are 1.54, 2.04 and 2.55 respectively and the peak positions for pure $\mathrm{C}$ and $\mathrm{TiC}$ are 285.5 and $281.9 \mathrm{eV}$ 
respectively, then the position of the $\mathrm{C}$ component at $282.9 \mathrm{eV}$ is indicative of $\mathrm{C}$ bonding to both $\mathrm{Ti}$ and $\mathrm{B}$. The three observations described above: (i) peak shifts of the (001) and (100) peaks in the XRD spectra; (ii) increase of the B 1s peak position with increasing C content; (iii) $\operatorname{Ti}(\mathrm{B}, \mathrm{C})_{\mathrm{x}}$ stoichiometry; are all consistent with the formation of a metastable $\mathrm{Ti}(\mathrm{B}, \mathrm{C})_{2}$ phase in addition to DLC.

Thus, a two phase $\operatorname{Ti}(\mathrm{B}, \mathrm{C})_{2}+$ DLC coating has been deposited. In contrast to the Ti-B-N and Ti-Al-B-N coatings, these Ti-B-C coatings have a phase composition which is not in agreement with the phase diagram. However, Holleck and Lahres have predicted the formation of $\mathrm{Ti}(\mathrm{B}, \mathrm{C})_{2}$ for similar compositions at such deposition temperatures using phase field diagrams [19].

The free energy of formation, ${ }^{\mathrm{f}} \Delta \mathrm{G}^{0}{ }_{298}$, of $\mathrm{TiB}_{2}$ is $-317 \mathrm{~kJ} / \mathrm{mol}$, whereas that of graphite is $0 \mathrm{~kJ} / \mathrm{mol}^{\mathrm{f}}{ }^{\mathrm{f}} \Delta \mathrm{G}^{0}{ }_{298}$ of metastable $\mathrm{Ti}(\mathrm{B}, \mathrm{C})_{2}$ is likely to be somewhat similar to $\mathrm{TiB}_{2}$ and ${ }^{\mathrm{f}} \Delta \mathrm{G}^{0}{ }_{298}$ of DLC will be very similar to graphite. Consequently, during film growth, there is a driving force for $\mathrm{C}$ to substitute into the hexagonal $\mathrm{TiB}_{2}$ phase rather than forming a pure $\mathrm{C}$ phase. This results in the DLC phase forming only when there is excess C; i.e. when no more $\mathrm{C}$ can be accommodated in the $\operatorname{Ti}(\mathrm{B}, \mathrm{C})_{2}$ phase. A plot of DLC content vs. total $\mathrm{C}$ content has shown this to be the case $[17,18]$.

The formation of $\mathrm{Ti}(\mathrm{B}, \mathrm{C})_{2}$ rather than $\mathrm{TiB}_{2}$ is detrimental to the mechanical properties of these coatings. A friction reducing effect is observed only at total $\mathrm{C}$ concentrations above 50-60 at.\%. Below this value, not sufficient lubricant phase was available, as increasing 
$\mathrm{C}$ incorporation into the $\mathrm{Ti}(\mathrm{B}, \mathrm{C})_{2}$ phase caused the concentration of low-friction DLC phase to remain below $<15$ at. $\%$. Coating $5(60$ at. $\%$ C) offered the best combined hardness $(20 \mathrm{GPa})$ and low-friction $(<0.2)$ properties [17].

\subsection{The Cr-Cu-N System}

Most protective coatings are ceramic compounds exhibiting a high hardness and elastic modulus. However, it is well known that a high $\mathrm{H} / \mathrm{E}$ ratio is an indicator of good wear resistance for a wide range of materials [20]. Consequently, desirable properties for many coatings are a relatively high hardness combined with a relatively low elastic modulus (similar to that of the underlying metallic substrate) [21]. As grain size reduction leads to an inherent increase in hardness (the Hall-Petch effect), nanostructuring materials which are predominantly metallically bonded could lead to coatings with a sufficiently high hardness to offer good protection, high toughness and an elastic modulus similar to the substrate.

The equilibrium $\mathrm{Cr}-\mathrm{Cr}$ phase diagram given in Fig. 8 shows only a small solubility of $\mathrm{Cr}$ in $\mathrm{Cu}$ [22]. Rebholz et al have shown that reactive sputter deposition of $\mathrm{Cr}$ can result in up to 16 at.\% $\mathrm{N}$ being interstitially incorporated within the $\mathrm{Cr}$ phase as $\mathrm{Cr}(\mathrm{N})$ [23]. $\mathrm{Cu}$ does not readily form a nitride phase. Consequently, the design concept for these coatings was to deposit hardened $\mathrm{Cr}(\mathrm{N})$ nanocrystallites embedded within a minority amorphous matrix of $\mathrm{Cu}$ by reactive sputtering of $\mathrm{Cr}$ and $\mathrm{Cu}$,. Five coatings were reactively co- 
sputtered from $\mathrm{Cr}$ and $\mathrm{Cu}$ targets at a substrate temperature of $300-350{ }^{\circ} \mathrm{C}$ [3]. The $\mathrm{Cr} / \mathrm{Cu}$ compositions are given in Fig. $7(\mathrm{Cu}$ content ranging from $2-55$ at. \%) and the $\mathrm{N}$ content across the range of coatings varied between 18 and 23 at. \%. XRD spectra showed $\mathrm{Cr}-\mathrm{Cu}-\mathrm{N}$ coatings 1 to 3 (3- 8 at. \% Cu respectively) to contain two nanocrystalline phases $-\mathrm{Cr}(\mathrm{N})$ and $\mathrm{Cr}_{2} \mathrm{~N}$.

Increasing the $\mathrm{Cu}$ content to 23 at. \% (coating 4), gave rise to the most interesting nanostructure and mechanical properties. The XRD spectrum exhibited a single broad peak, providing little information on structure. However, a dark field TEM image was obtained using the overlapping $\alpha-\mathrm{Cr}(110)$ and $\beta-\mathrm{Cr}_{2} \mathrm{~N}$ (200) reflections (Fig. 9). The nanocrystallite phase composition cannot be unambiguously determined from the electron diffraction pattern, but is probably a mixture of $\mathrm{Cr}(\mathrm{N})+\mathrm{Cr}_{2} \mathrm{~N}$. The nanocrystallite size is very fine and uniform; there is a strong preferential orientation of the nanocrystallites and their average grain size is approximately $2 \mathrm{~nm}$.

Even at 23 at.\%, $\mathrm{Cu}$ has not formed as a separate nanocrystalline phase. Considering the low solid state miscibility of $\mathrm{Cr}$ and $\mathrm{Cu}$, very fine nanostructure and moderate deposition temperature, it may be expected that the majority of $\mathrm{Cu}$ atoms lie at grain boundaries. The $\mathrm{Cu} 2 \mathrm{p}_{3 / 2}$ peak position, at $932.7 \mathrm{eV}($ elemental $\mathrm{Cu})$, is also in accordance with $\mathrm{Cu}$ cluster formation. Thus, a nanocomposite structure comprised of a $\mathrm{Cr}(\mathrm{N})+\mathrm{Cr}_{2} \mathrm{~N}$ nanocrystalline component and a $\mathrm{Cu}$ amorphous component can be assumed. 
In the general nanocomposite design proposed by Veprek [2], the critical concentration of amorphous phase required to achieve complete monolayer coverage of the nanocrystallites will vary with grain size. To assist in the understanding of the nanostructure forming in these coatings, hypothetical calculations have been undertaken to determine the critical concentration of $\mathrm{Cu}$ required for complete monolayer coverage of nanocrystalline $\mathrm{Cr}$ grains in an idealised $n c-\mathrm{Cr} / a-\mathrm{Cu}$ structure. Calculations have been undertaken assuming the $\mathrm{Cu}$ monolayer to adopt one of two 2-D packing densities: simple square packing and hexagonal close packing. The actual packing density is probably random close packing, which would give rise to a packing density between these two ordered arrangements. A full description of this calculation is given in [3]. To summarise, for cubic shaped grains, the $\mathrm{Cu}$ concentration $\mathrm{C}_{\mathrm{Cu}}$ (at.\%) required for complete simple cubic packing monolayer coverage of $\mathrm{Cr}$ grains with a diameter, $d$, is given by:

$$
C_{C u}=\left(\frac{\pi r_{C r}^{3}}{\pi r_{C r}^{3}+p d r_{C u}^{2}}\right) \times 100
$$

where $r$ is the atomic radius (being taken as 0.125 and $0.128 \mathrm{~nm}$ for $\mathrm{Cr}$ and $\mathrm{Cu}$ respectively), and $p$ is the packing density (e.g. 0.68 for b.c.c. Cr). For hexagonal close packing, the $\mathrm{Cu}$ concentration is given by:

$$
C_{C u}=\left(\frac{2 \pi r_{C r}^{3}}{2 \pi r_{C r}^{3}+\sqrt{3} p d r_{C u}^{2}}\right) \times 100
$$


For a grain diameter of $3 \mathrm{~nm}$, these equations give rise to $\mathrm{Cu}$ concentrations of 15.5 and 17.5 at.\% for simple cubic and hexagonal close packing respectively. In Fig. 9, the mean value of the two packing densities (approximating to random close packing) is plotted as a function of grain size.

All nanocomposite systems will exhibit similar volume/surface area ratio effects as a function of grain size. From inputting a selection of different atomic radii (for different hypothetical systems), similar trends in the dependence of amorphous phase concentration with grain size are observed and the data fits well to either a power or logarithmic function for the different systems.

Although the results should clearly be treated as approximations, Fig. 9 suggests that $\approx 23$ at. $\% \mathrm{Cu}$ is sufficient for monolayer coverage in an a $n c-\mathrm{Cr} / a-\mathrm{Cu}$ nanocomposite with a mean grain size of $2 \mathrm{~nm}$ (i.e. similar to coating 4). However, distinct preferential orientation of the nanocrystallites is observed for this coating, which would probably be promoted by incomplete rather than complete grain coverage. Consequently, the analytical results indicate that coating 4 has a nanostructure approaching that of $\alpha-\mathrm{Cr}(\mathrm{N})$ $+\beta-\mathrm{Cr}_{2} \mathrm{~N}$ separated by a $\mathrm{Cu}$-rich amorphous grain boundary layer. However, the $\mathrm{Cu}$ may be clustered rather than forming a uniform monolayer.

The 23 at. $\% \mathrm{Cu}$ coating performed best in reciprocating-sliding and impact wear tests. The impact resistance showed a factor of 3 improvement over the other $\mathrm{CrCuN}$ coatings and was more than 30 times better than single phase $\mathrm{Cr}(\mathrm{N})$ [3]. This enhanced wear 
resistance can be attributed to a relatively high hardness (18 GPa) combined with excellent fracture toughness and adhesion to the substrate.

\section{Conclusions}

By presenting results on analytical investigations into Ti-Al-B-N, Ti-B-C and $\mathrm{Cr}-\mathrm{Cu}-\mathrm{N}$ coating systems, a combination of electron spectroscopic, microscopic and diffraction techniques has provided a reasonably comprehensive characterisation of the structure and phase composition of nanocomposite coatings. Phase diagrams are important in coating design, but the non-equilibrium vapour deposition process can often lead to deviations from structures predicted purely on this basis. Quantifying XPS spectra to yield relative phase fractions and careful interpretation of the spectroscopic and diffraction data to identify metastable phases or defective structure is essential for reliable process-structureproperty relationships to be established. Nanocomposite coatings exhibit enhanced mechanical properties, but optimisation and further advances are dependent upon sound characterisation and a good understanding of the nanostructures formed.

\section{Acknowledgements}

The author would like to acknowledge the invaluable contributions of his co-workers at the Surface Engineering Unit, EU Institute of Advanced Materials, Ispra, Italy, University of Sheffield, UK and University of Surrey, UK in providing samples, acquiring data and discussing ideas presented throughout this paper. 


\section{References}

[1] P.Hammer, A.Steiner, M.A.Baker, P.N.Gibson, J.Haupt, W.Gissler Surface and Coatings Technology 68/69 (1994) 194

[2] S. Vepřek J. Vac. Sci. Technol. A 17 (1999) 2401

[3] M.A.Baker, P.J.Kench, C.Tsotsos, P.N.Gibson, A.Leyland, A.Matthews J. Vac. Sci. Technol. A 23 (2005) 423

[4] Y.T.Pei, D. Galvan, J.T.M. De Hosson, A. Cavaleiro Surface and Coatings

Technology 198, (2005) 44-50

[5] A. A. Voevodin, T. A. Fitz, J. J. Hu, J. S. Zabinski J. Vac. Sci. Technol. A 20 (2002) 1434

[6] T.H. de Keijser, E.J.Mittemeijer, H.C.Rozendaal J. Appl. Cryst. 16 (1983) 309

[7] H. Novotny, F. Benesovsky, C. Brukl, O. Schob Monatash Chem. 92 (1961) 403

[8] M.A.Baker, C.Rebholz, A.Leyland, A.Matthews Vacuum 67 (2002) 471

[9] M.A.Baker, T.P.Mollart, P.N.Gibson, W.Gissler J. Vac. Sci. Technol. A 15 (1997) 284

[10] M.A.Baker, A.Steiner, J.Haupt, W.Gissler J. Vac. Sci. Technol. A 13 (1995) 1633

[11] http://srdata.nist.gov/xps/

[12] M.A.Baker, M.A.Monclus in preparation

[13] K.B.Panda, K.S.R.Chandran Comp. Mat. Sci. 35 (2006) 134

[14] K.B.Panda, K.S.R.Chandran Acta Materialia (2006) on-line 
[15] P.H.Mayrhofer, M.Stoiber, C.Mitterer Scripta Materialia 53 (2005) 241

[16] M.A.Baker, S.Klose, C.Rebholz, A.Leyland, A.Matthews Surface and Coatings Technology 151-152, (2002) 338

[17] R.Gilmore, M.A.Baker, P.N.Gibson, W.Gissler Surface and Coatings Technology 105 (1998) 45

[18] M.A.Baker, R.Gilmore, P.N.Gibson, W.Gissler ECASIA ‘97 (Eds. I.Olefjord, L.Nyborg, D.Briggs) Gothenburg, Sweden, Wiley, Chichester, U.K. (1997) 1127

[19] H.Holleck, M.Lahres Mat. Sci. Eng. A140 (1991) 609

[20] T.L.Oberle J.Metallurgy 3 (1951) 438

[21] A.Leyland, A.Matthews Wear 246 (2000) 1

[22] Binary Alloy Phase Diagrams T.B.Massalski, J.L.Murray, L.H.Bannet and H.Baker (Eds.) ASM, Metals Park, OH, USA (1986)

[23] C.Rebholz, H.Ziegele, A.Leyland, A.Matthews Surface and Coatings Technology 115 (1999) 222 


\section{Figure and Table Captions}

Table 1: Relative phase fractions for the TiAlBN coatings, calculated from the stoichimetry (calc.) and experimentally determined from curve fitting of the XPS B and $\mathrm{N}$ 1s peaks (exp.)

Figure 1: A modified Ti-B-N equilibrium phase diagram of Novotny et al [6] accounting for the known substitution of $\mathrm{Al}$ for $\mathrm{Ti}$ in $(\mathrm{Ti}, \mathrm{Al}) \mathrm{N}$. The TiAlBN coating compositions are marked.

Figure 2: GAXRD spectra for the TiAlBN coatings, showing the presence of the f.c.c. (Ti,Al)N phase for all coatings. (Ti,Al)N grain sizes (G.S.) are indicated.

Figure 3: Curve fitted XPS B and N 1s peaks for the TiAlBN coatings

Figure 4: XPS B 1s peak for the TiAlBN coatings. Note the emergence of a new component at $185.9 \mathrm{eV}$ as the $\mathrm{B}$ content is reduced

Figure 5: The equilibrium Ti-B-C phase diagram of Novotny et al [6]. The TiBC coating compositions are marked. 
Figure 6: GAXRD spectra for the TiBC coatings. Grain sizes (G.S.) are given for the 18 and 61 at. $\% \mathrm{C}$ containing coatings.

Figure 7: XPS C and B 1s peaks for coating 2

Figure 8: The equilibrium $\mathrm{Cr}-\mathrm{Cu}$ phase diagram taken from Massalski et al [21]. The $\mathrm{CrCuN}$ coating compositions are marked.

Figure 9: (a) TEM plan view dark field image of $\mathrm{CrCuN}$ coating 5; (b) A higher magnification image of (a)

Figure 10: A plot of the atomic concentration of $\mathrm{Cu}$ required for monolayer coverage of $\mathrm{Cr}$ grains as a function of grain size in a hypothetical $n c-\mathrm{Cr} / \mathrm{a}-\mathrm{Cu}$ nanocomposite coating. The $\mathrm{Cu}$ concentrations plotted are the mean value of those calculated for simple cubic and hexagonal close packing densities (approximating to random close packing). 
Elemental

Sample Concentrations (at.\%)

Relative Phase Fractions

$\mathrm{Ti} \quad \mathrm{Al} \quad \mathrm{B} \quad \mathrm{N}$

$(\mathrm{Ti}, \mathrm{Al}) \mathrm{N}$

$\mathrm{BN}$

$\mathrm{TiB}_{2}$

Calc. Exp. Calc. Exp. Calc. Exp.

$\begin{array}{lllllllllll}1 & 10.1 & 11.4 & 29.1 & 49.4 & 42 & 46 & 57 & 52 & 1 & 2\end{array}$

$\begin{array}{lllllllllll}2 & 16.8 & 9.0 & 26.4 & 47.8 & 50 & 55 & 47 & 42 & 3 & 3\end{array}$

$\begin{array}{lllllllllll}3 & 25.3 & 10.1 & 16.0 & 48.6 & 70 & - & 29 & - & 2 & -\end{array}$

$\begin{array}{lllllllllll}4 & 36.2 & 8.0 & 6.2 & 49.5 & 88 & 88 & 11 & 11 & 1 & 1\end{array}$

$\begin{array}{lllllllllll}5 & 39.1 & 7.2 & 4.2 & 49.5 & 92 & 90 & 7 & 8 & 1 & 2\end{array}$

Table 1 


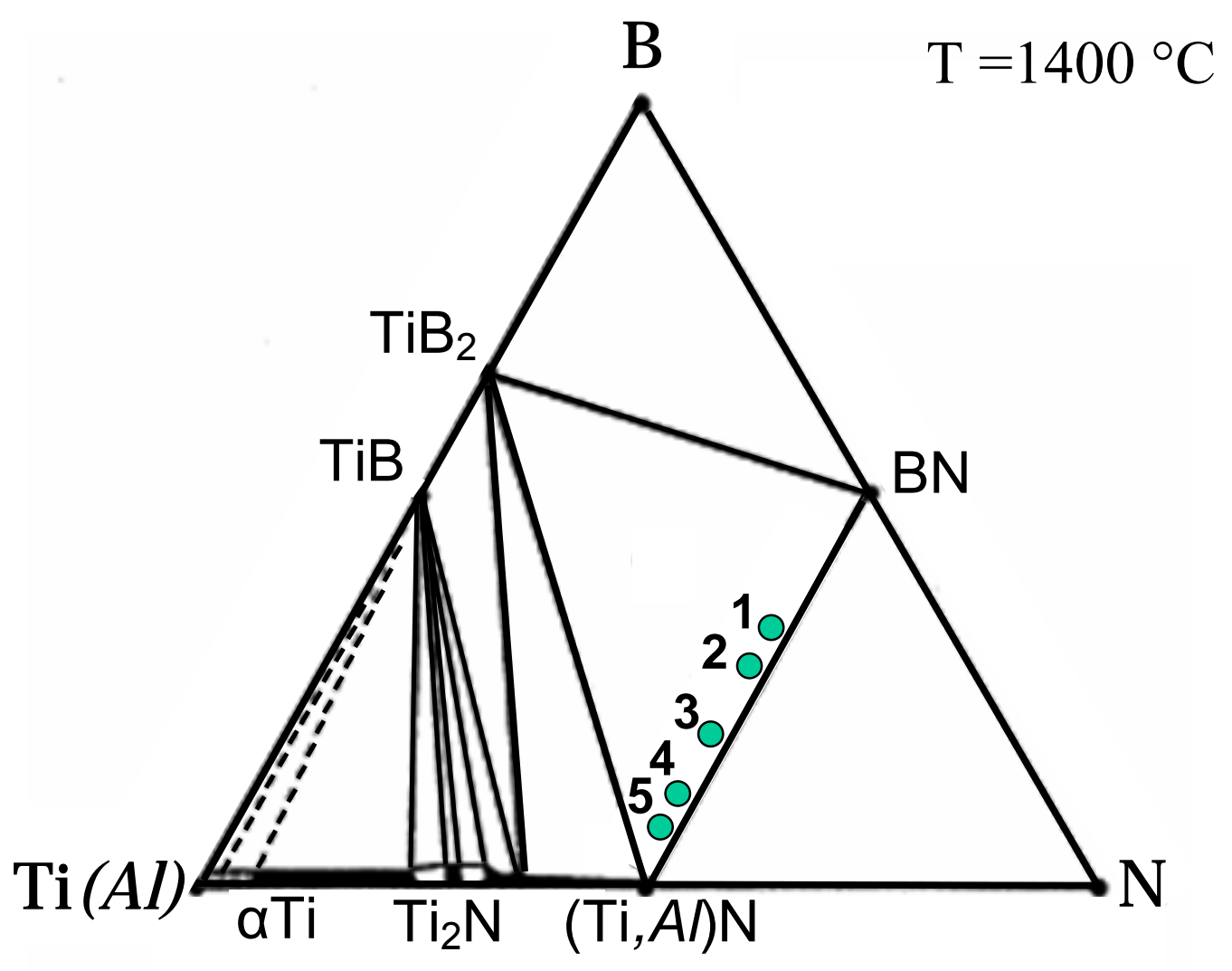

Figure 1 


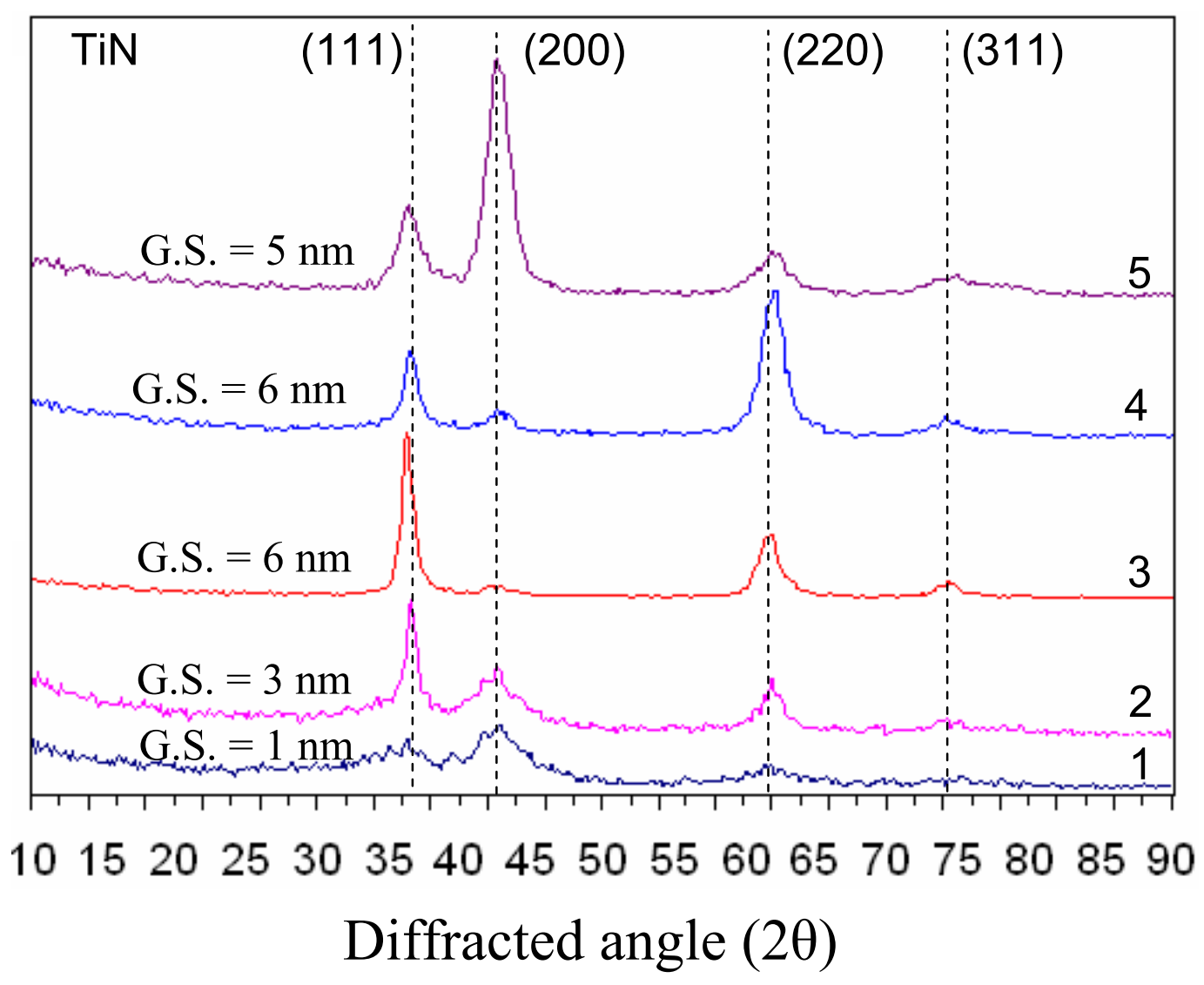

Figure 2 

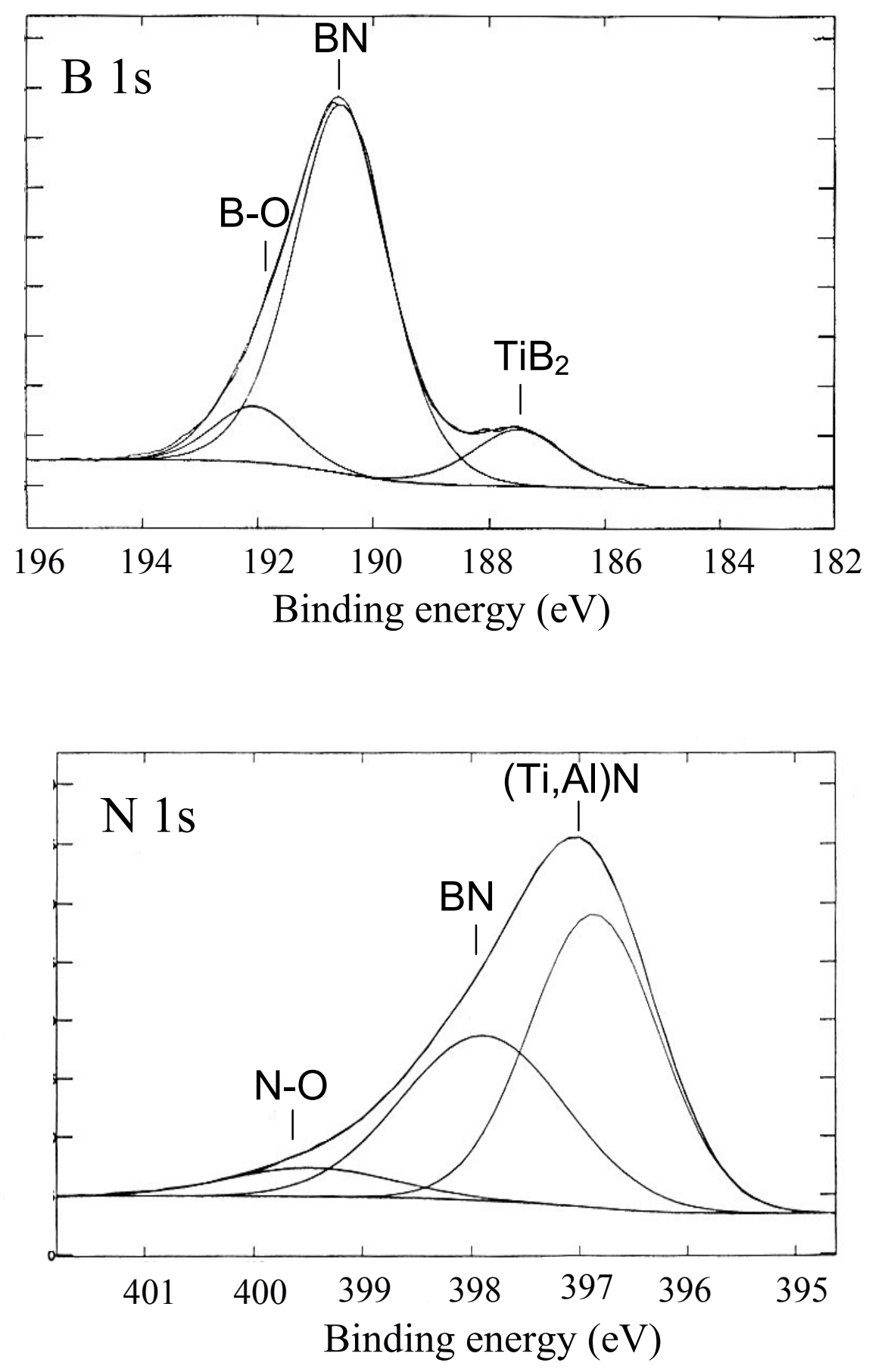

Figure 3 


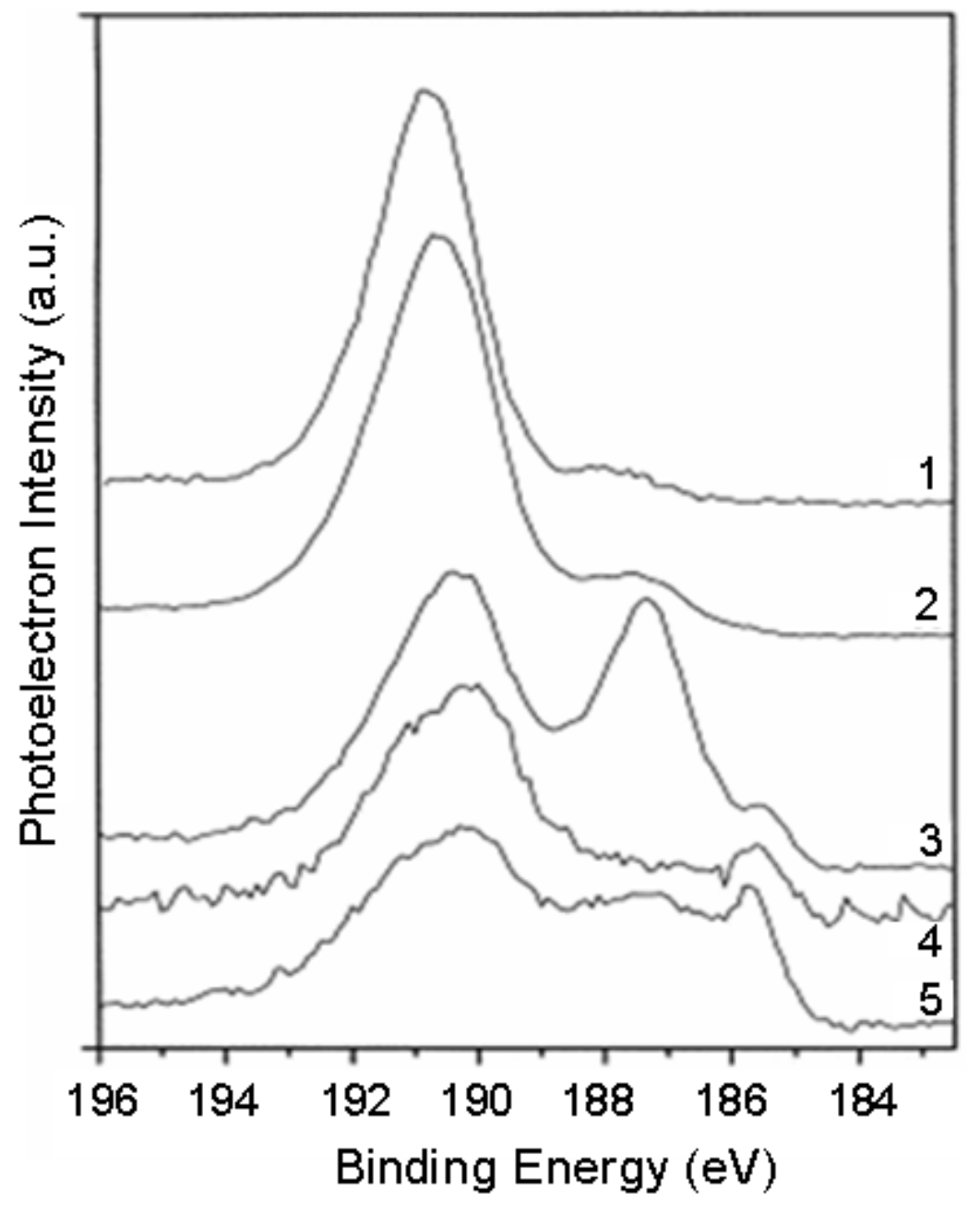

Fig. 4 


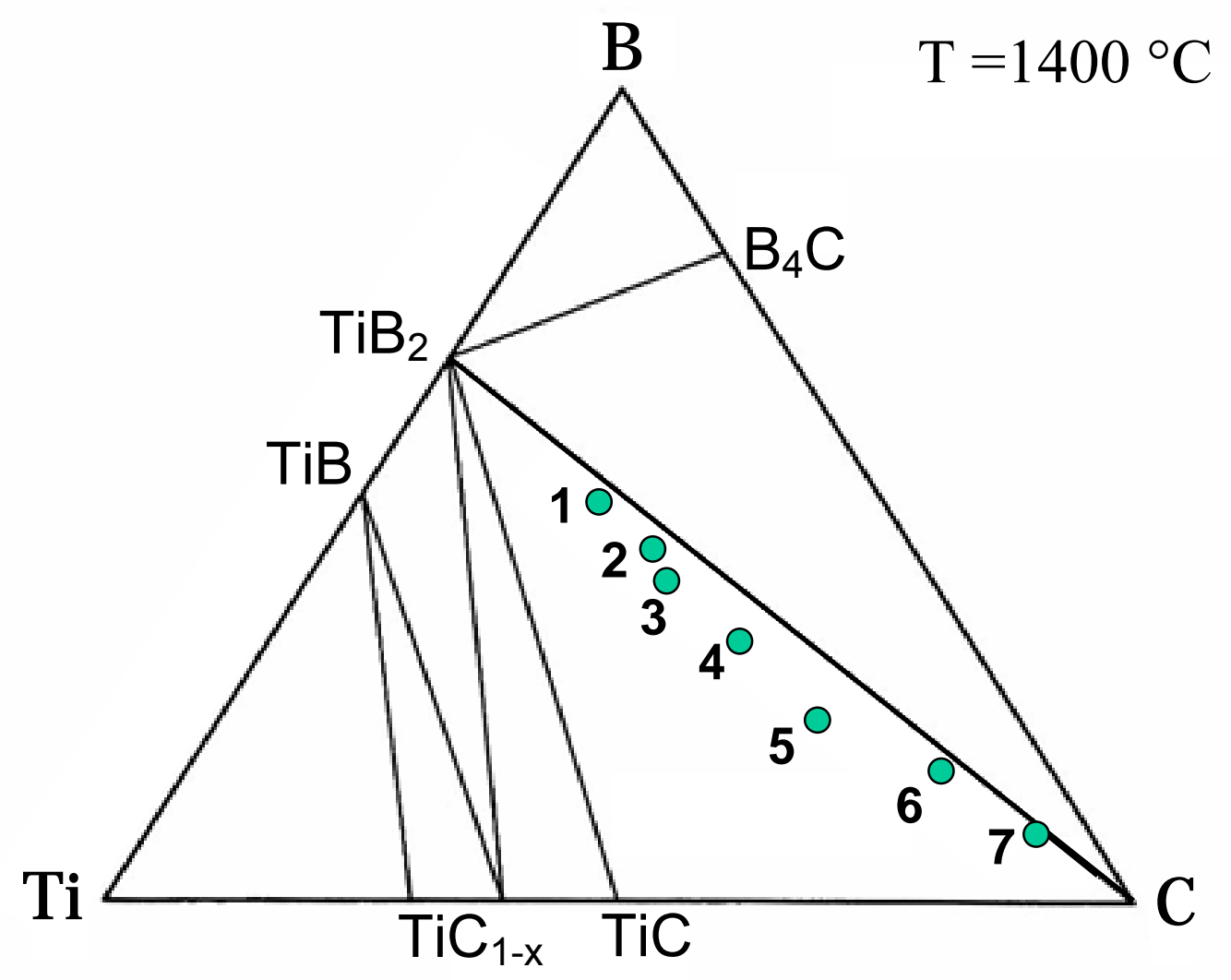

Figure 5 


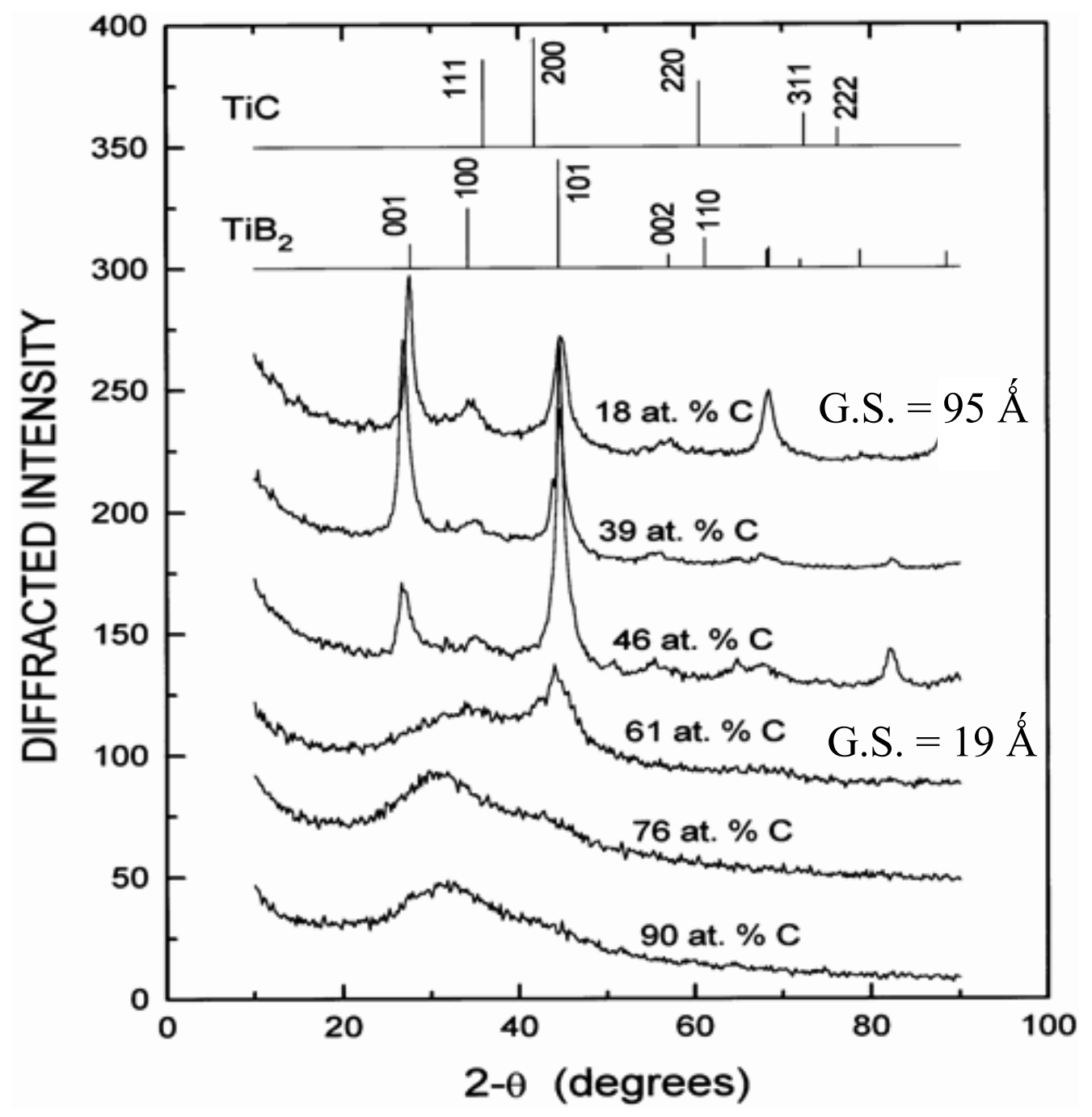

Figure 6 

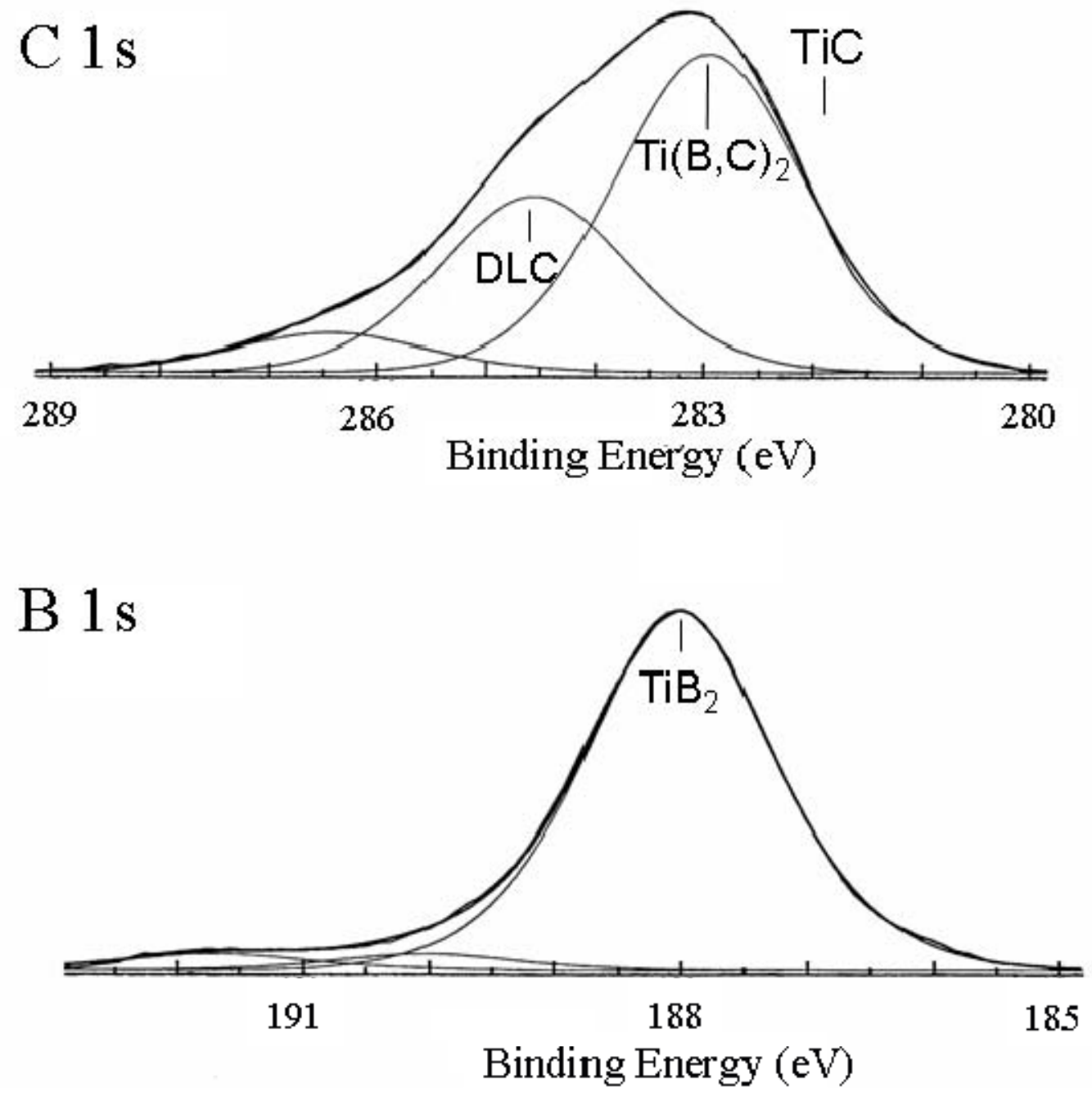

Figure 7 


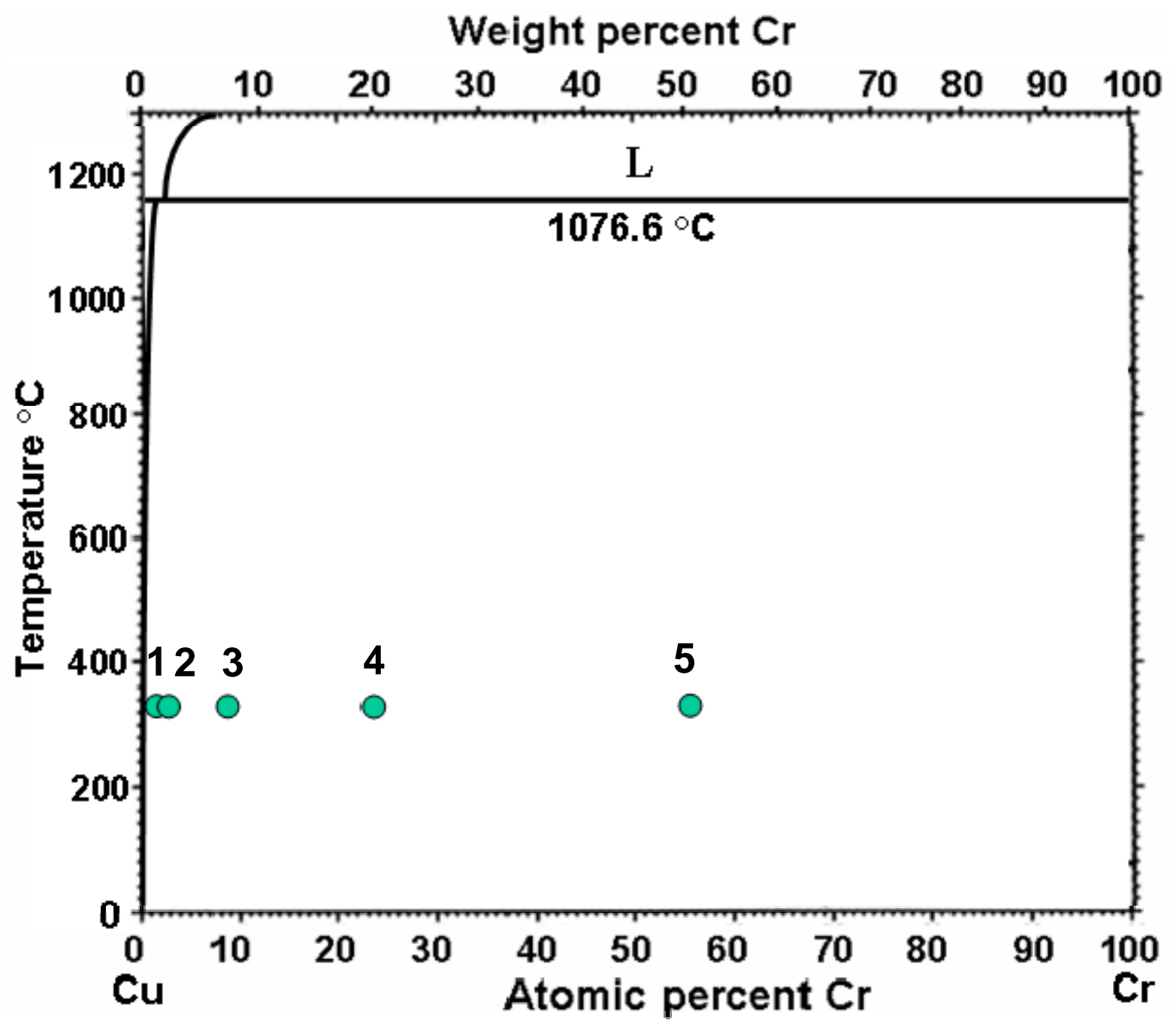

Figure 8 


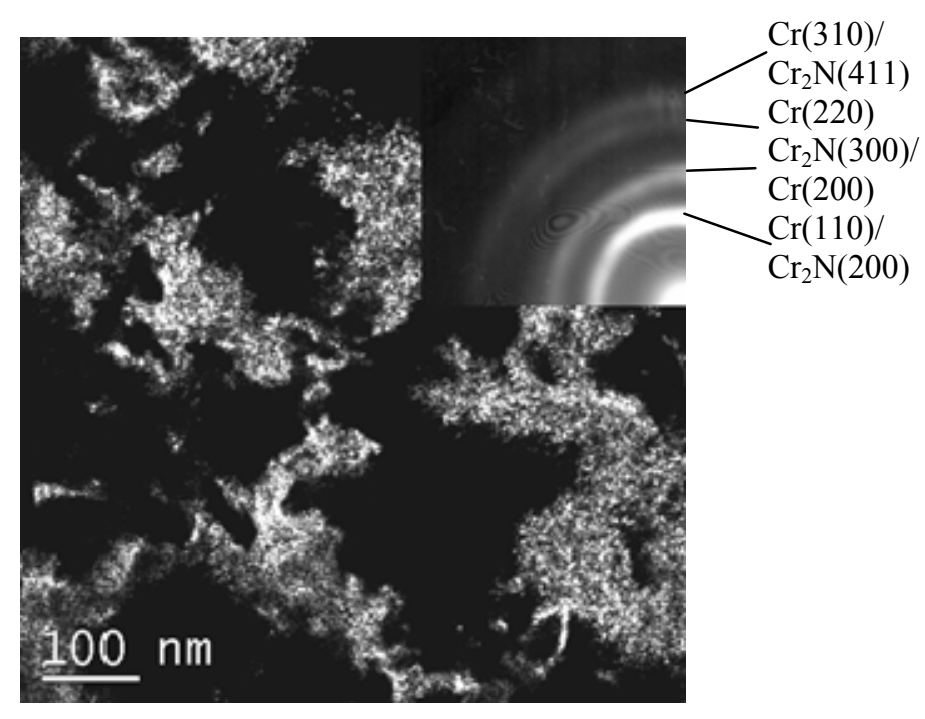

(a)

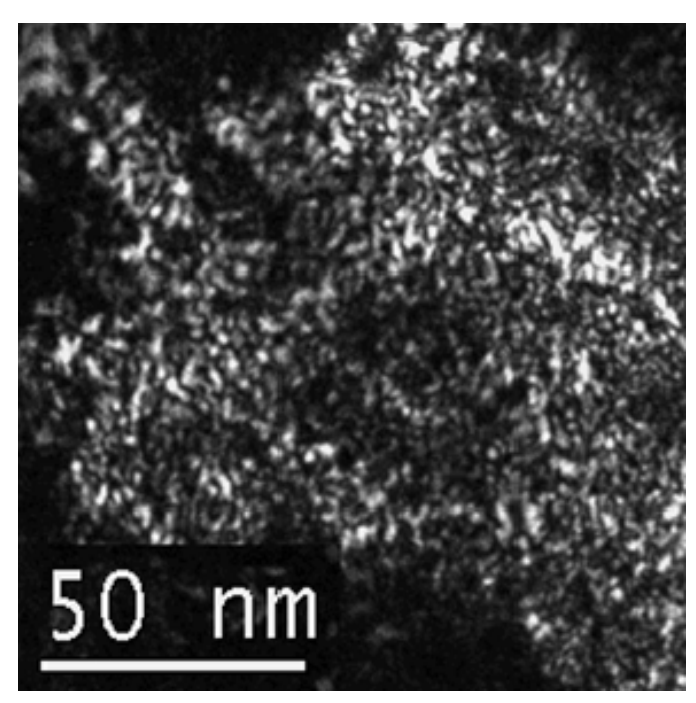

(b)

Fig. 9 


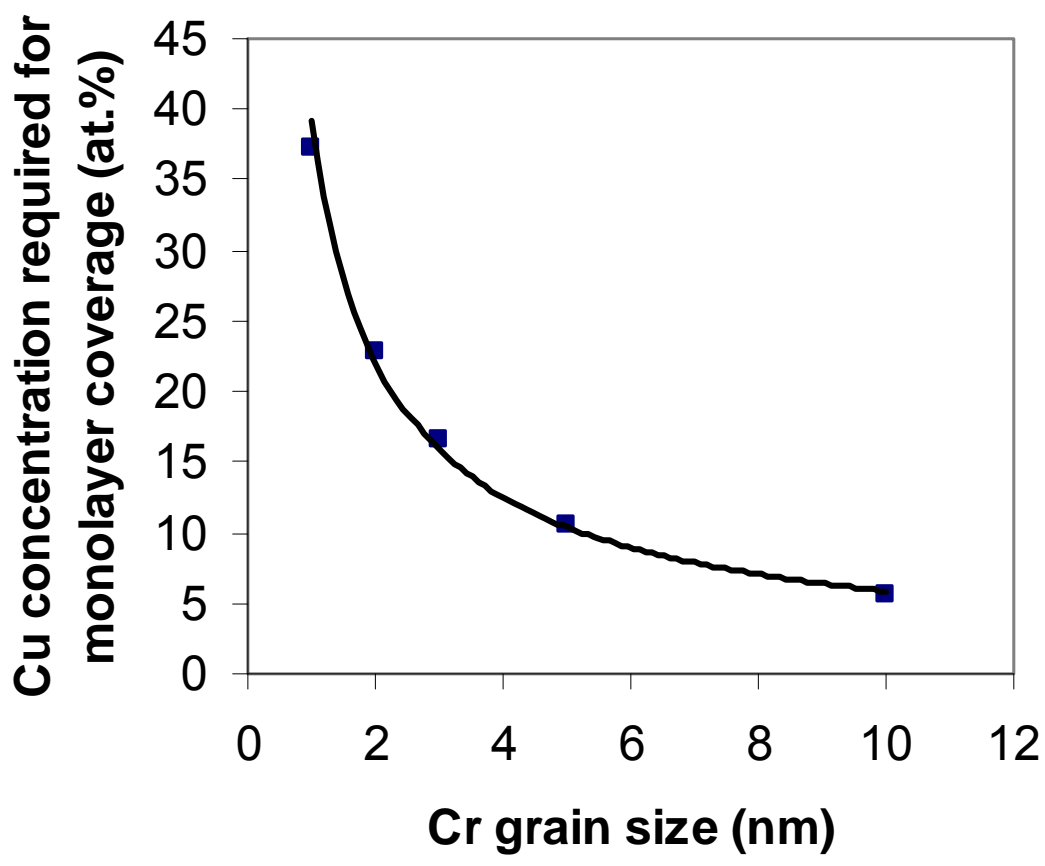

Fig. 10 